\title{
INTERNET, NARCISISMO E SUBJETIVIDADE: REFLEXõES SOBRE A Constituição Do Sujeito Na/Pela Rede Social
}

\author{
Ana Paula Grillo Rodrigues' \\ Luhilda Ribeiro Silveira² \\ Cássio Araújo Correa ${ }^{3}$
}

\section{RESUMO}

A internet com seu potencial de hiper conectividade trouxe reflexos não só para o estilo de vida das sociedades, mas também para a própria construção do sujeito e modos de subjetivação na contemporaneidade. Nesse cenário, destacamos o uso de redes sociais, como Instagram, que se expandiu rapidamente, se tornando fenômeno mundial, e que faz parte desse novo contexto de construção da subjetividade. $\mathrm{O}$ presente artigo constitui-se em um ensaio teórico, que teve como objetivo esboçar um olhar sobre a constituição do sujeito, considerando aqui os aspectos da teoria psicanalítica, vislumbrando possíveis articulações entre essa teoria e os aspectos da hiper conectividade das redes sociais onde esse sujeito está imergindo, especialmente no Instagram.

PalaVRas-ChaVe: Internet; Redes Sociais; Instagram; Subjetividade; Narcisismo.

\footnotetext{
1 Doutorado em Administração Pública / UFBA. Mestrado em Administração / UFSC. Graduação em Psicologia / UFSC. Professora efetiva da Universidade UDESC. Professora dos cursos de mestrado da FAED e ESAG da UDESC. E-mail: agrillorodrigues@gmail.com Telefone: (48) 988282752

2 Mestrado em Gestão de Unidades de Informação / UDESC. Graduação em Biblioteconomia / UFMA. Graduação em Psicologia / UFMA. Bibliotecária do Núcleo Integrado de Bibliotecas da UFMA. E-mail: luhida@yahoo.com.br Telefone: (98) 988488612

${ }^{3}$ Especialização em Neuropsicopedagogia pela Faculdade Cândido Mendes. Graduação em Psicologia / UFMA. Psicólogo da Secretaria de Administração Penitenciária (SEAP) do Maranhão. E-mail: cassiopsi@outlook.com Telefone: (98) 984248441
} 


\section{INTRODUÇÃO}

A chamada era da informação, mediada pelas redes de computadores interligadas à internet, transformaram de um modo considerável a sociedade em vários aspectos. $E$ toda essa hiper conectividade trouxe reflexos não só para o modo de vida das sociedades, mas também para a própria construção do sujeito e modos de subjetivação na contemporaneidade.

O acesso à internet, que inicialmente foi favorecido devido à fabricação de computadores em larga escala e ao seu aperfeiçoamento, bem como à redução do preço, faz com que na atualidade vivamos um momento em que o computador deixou de ser o principal meio de acesso à internet, e abriu espaço para novos modos de acesso à rede por meio de tablets, smartphones, dentre outros equipamentos eletrônicos. Tudo isso possibilitou que ficássemos cada vez mais conectados em um mundo online, compondo o que Castells (1999) denominou de "a sociedade em rede", reforçando a máxima posta por ele de uma "cultura da virtualidade real", onde realidade e virtualidade se misturam e compõem o cenário comunicacional e das relações humanas.

No universo de possibilidades que a internet oferece, chama-nos a atenção o uso de redes sociais, especialmente o Instagram, rede social desenvolvida em 2010 pelos jovens norte-americano Kevin Systrom e o brasileiro Mike Krieger. Em 2012 o Instagram foi comprado pelo Facebook e, desde 2018 esta rede social conta com mais 1 bilhão de usuários no mundo e, segundo estimativas, o Brasil possui cerca de 64 milhões, ocupando o terceiro lugar no ranking mundial desta rede social. (TARDÁGUILA, 2019).

O Instagram é uma rede social para postagens e compartilhamentos de fotos e vídeos com possibilidade de aplicação de filtros digitais. Cada usuário dessa rede possui um mural para realização de suas postagens, que podem ser visualizadas, curtidas, comentadas e compartilhadas pelos seus seguidores - denominação dada àqueles que desejam acompanhar as postagens de outro usuário.

Nessa perspectiva, pensar nos modos como as pessoas utilizam essa rede social, e em especial, como elas estão sendo afetadas em sua constituição psíquica a partir dos usos e (des)usos dessa ferramenta é uma possibilidade de análise do sujeito na contemporaneidade. 
INTERNET, NARCISISMO E SUBJETIVIDADE: REFLEXões SOBRE A CONSTITUIÇÃo Do SUJEITO NA/PELA REDE SOCIAL

Pensar aspectos da constituição do sujeito na sociedade em meio à tecnologia e mais especificamente nessa "sociedade em rede" é um desafio que traz consigo questões tão recentes quanto impactantes em nossa sociedade. O Instagram é um fenômeno em termos de popularidade e influência para a sociedade e se constitui num aspecto marcante da contemporaneidade, que está cada vez mais imersa em tais canais. Isso nos impulsiona a pensar e ampliar horizontes de discussões no que tange à constituição do sujeito nesse contexto. Quais influências estão em jogo na constituição do sujeito a partir das interações mediadas por essa rede social? Como a construção da imagem é afetada pelo uso da rede social? Que aspectos relevantes e/ou peculiares podemos observar nesse cenário?

As perguntas acima colocadas giram fundamentalmente em torno de como 0 uso das redes sociais, em especial o Instagram, está afetando a dinâmica da constituição dos sujeitos e de que forma estes fatores podem afetar suas relações. $E$ é em meio a tais questionamentos que propomos neste estudo esboçar um olhar que tangencia o sujeito considerando aspectos da teoria psicanalítica e vislumbrando possíveis articulações com o Instagram.

\section{REDES SOCIAIS E CONTEMPORANEIDADE}

As formas como nos comunicamos e interagimos na sociedade reflete os avanços científicos e tecnológicos de uma dada época, e mais do que simplesmente inaugurar novos contextos informacionais possibilita, dentre outras coisas, a quebra de barreiras de tempo e espaço no panorama da comunicação e da informação. Além disso, trouxe novos contornos para o sujeito que se insere nesse contexto. É possível hoje perceber facilmente as influências que o contexto das redes sociais trouxe para a vida em vários aspectos da sociedade. É salutar observar que na atualidade as pessoas estão sendo inseridas cada vez mais cedo no cenário cibernético, e desde cedo sua configuração subjetiva é influenciada por esses recursos que situam a vida entre o real e virtual. Mas seria o mundo virtual, um mundo não real?

Pierre Lévy (1996) propôs uma explicação que colocaria em cheque o que ele denomina de "oposição fácil e enganosa entre real e virtual", pois para ele o virtual, ou a virtualização é "o movimento inverso da atualização", tendo em vista sua discordância de que o virtual seja a ausência de realidade. Para Lévy o virtual seria 
marcado pela potência.

O virtual tende a atualizar-se, sem ter passado no entanto pela concretização efetiva ou formal. A árvore está virtualmente na semente. Em termos rigorosamente filosóficos, o virtual não se opõe ao real mas ao atual: virtualidade e atualidade são apenas duas maneiras de ser diferentes (LÉVY, 1996, p.15).

Seguindo uma lógica da não qualificação quanto ao cenário que a tecnologia vem imprimindo à sociedade, Castells (2003) defende que diante do cenário da contemporaneidade estão emergindo novos padrões de sociabilidade possibilitados por novos recursos tecnológicos que estão criando a sociedade em rede. Contudo, ele afirma que os custos de tais padrões ainda são obscuros para a sociedade.

\section{A Construção do Sujeito Pela Ótica Da Psicanálise}

O psicanalista francês Jacques Lacan, em seu retorno a Freud, utilizou teorias outras como recurso para abordar 0 inconsciente freudiano, dentre elas 0 estruturalismo antropológico de Levi Strauss e a Linguística de Saussure. Essas duas perspectivas são importantes na medida em que elas possibilitam entender momentos cruciais da constituição do sujeito que serão tratadas neste artigo, fundamentadas pelo texto "O estádio do espelho como formador da função do eu" (LACAN, 1949), bem como nas elaborações de Freud a respeito do "Complexo de Édipo".

A primeira relação de realidade para a criança desenha-se entre ela, a mãe e o falo. Trata-se do estádio do espelho, onde Lacan utilizou a metáfora do espelho para explicar como a criança, em sua relação com a mãe constitui o seu Eu. Essa criança, num primeiro momento, ainda com pouco ou nenhum domínio do seu corpo, precipitarse-á na imagem da mãe como primeiro momento de contato com a realidade (LACAN, 1998). A mãe, ou a pessoa que responsável pela maternagem, emprestará sua imagem e sua palavra para que o Eu da criança se constitua, daí Lacan afirmar que Eu é Outro. Lacan esclarece que "[...] o Outro é o lugar em que se situa a cadeia significante que comanda tudo que vai poder se presentificar do sujeito, é o campo desse vivo onde o sujeito tem que aparecer" (LACAN, [1964] 1998, p. 200). Em outras palavras, é o campo da própria linguagem.

Com essa metáfora, Lacan mostrará que a constituição do sujeito se dá pela via do grande Outro, escrito com O maiúsculo. Inicialmente, a mãe ou a pessoa que 
INTERNET, NARCISISMO E SUBJETIVIDADE: REFLEXões SOBRE A CONSTITUIÇÃo Do SUJEITO NA/PELA REDE SOCIAL

ocupa a função materna, ocupará o lugar do Outro. Isso mostra que não se pode pensar a criança sem uma referência à mãe, que é responsável por introduzi-la no universo da linguagem. "[...] quando há um sujeito falante, não há como reduzir a um outro, simplesmente, a questão de suas relações com alguém que fala, mas há sempre um terceiro, o Grande Outro, que é constitutivo da posição do sujeito enquanto alguém que fala [...]" (LACAN, [1957-1958] 1999, p. 186).

O desejo da mãe é o desejo do filho. Essa mãe investe esse filho de desejo, colocado por ela no lugar do falo, objeto valorizado na cultura, que faz com que ela sinta completa. No processo de constituição do sujeito, pode-se dizer que esse período se estrutura pelo ternário imaginário: mãe, filho e falo. Contudo, essa mãe está submetida a uma lei, a lei simbólica, que demanda que ela se ausente, que impede que ela esteja o tempo todo com o filho, em razão de que há um mundo lá fora que a convoca. Ela precisa se ausentar, é nessa ausência/presença que a criança vai se dando conta de que a mãe é um sujeito desejante e que seu desejo se projeta para além dela. Esta dinâmica mostra que a criança e a mãe não são um único ser: instaura-se a falta; a mãe volta seu olhar para outro lugar porque existe algo que a mãe deseja para além desse filho. Frustra-se a criança. Pode-se dizer que aí se inicia o drama infantil: O Complexo de Édipo.

Lacan aborda o Complexo de Édipo pela via da linguagem mostrando que pai e mãe são significantes que dizem muito mais de funções do que de parentesco. A metáfora paterna introduz uma lei que barra a relação incestuosa da criança com a mãe. O Complexo de Édipo é um drama vivenciado pela criança responsável pela estruturação psíquica do sujeito: psicose, perversão ou neurose. Contudo esse percurso infantil é dinâmico, ou seja, coloca questões desde o início, antes mesmo desta criança nascer, pois, como sujeito de linguagem, ela já era falada antes mesmo de vir ao mundo e o peso desse discurso só é autenticado e atualizado no real de seu corpo, num depois.

Antes de qualquer experiência, antes de qualquer dedução individual, [...] algo organiza esse campo, nele inscrevendo linhas de força iniciais. [...] Antes ainda que se estabeleçam relações que sejam propriamente humanas, certas relações já estão determinadas. Elas se prendem a tudo que a natureza possa oferecer como suporte, suportes que se dispõem em termos de oposição. A natureza oferece, para dizer o termo, significantes, e esses significantes organizam de modo inaugural as relações humanas, dão-lhes as estruturas e as modelam [...] Antes de qualquer formação do sujeito, de 
um sujeito que pensa, que se situa aí- isso conta, é contado, e no contado já está o contador. [...] o jogo operatório operando em sua espontaneidade, sozinho, de maneira pré-subjetiva [...] (LACAN, [1964] 1998, p.26).

Após a criança se dar conta de que ela e a mãe não são Uma, abre a possibilidade para a saída dessa identificação primordial. "[...] o sujeito se identifica especularmente com aquilo que é objeto do desejo de sua mãe. Essa é a etapa 'fálica primitiva' [...]" (LACAN, [1957-1958] 1999, p. 198). Esse momento é crucial e a forma como ele é respondido pela mãe pode fundar-se num certo número de distúrbio e perturbações, como as identificações perversas.

A criança percebe que não é o objeto de desejo da mãe. Podemos caracterizar essa fase pela intromissão indireta do pai nesse ternário imaginário. Ocorre a primeira simbolização indireta porque a presença simbólica do pai se faz pela mediação da mãe. O pai priva a mãe de seu objeto. A relação da criança com o falo se dá na medida em que o falo é objeto de desejo da mãe, ou seja, seu desejo é o desejo do desejo da mãe. Cabe à criança aceitar ou recusar a privação do pai em relação à mãe, lembrando do cuidado em relação a esse aceitar, visto que a instituição da criança no mundo da linguagem só foi e é possível pelo discurso dos pais. O que cabe aqui à criança é a questão: ser ou não ser o falo. A criança questiona à mãe sobre o desejo dela. A resposta da mãe é imprescindível na determinação da criança em ser ou não o falo: a identificação com o falo. Isso depende do modo como a mãe responde a esta criança faltosa (Dá) quando ela retorna (Fort). Essa resposta é crucial para a entrada da criança na próxima fase: a castração (LACAN, [1957-1958] 1999).

Pensemos a próxima fase: esta está voltada para a díade ter ou não ter o falo. É a fase da castração. Não se trata de quem terá o pênis, mas o falo. O complexo de castração é o que rege essa fase, é dele que depende dois fatos: o fato de a menina se transformar em mulher e o fato de o menino transformar-se em homem. Mas para ter o falo, é necessário que haja um momento em que não se tenha, para que, assim, se coloque ao sujeito a possibilidade de ser castrado (LACAN, [1957-1958] 1999).

O pai que se mostra nesta etapa é o pai real revestido do símbolo da proibição. Contudo, o importante de ser mencionado como desfecho do complexo de Édipo, não é o fato da função do pai- Nome-do-Pai- está ligada à proibição do incesto, até mesmo porque a mãe já está no mundo da linguagem, ela pode muito bem mostrar à criança 
INTERNET, NARCISISMO E SUBJETIVIDADE: REFLEXões SOBRE A CONSTITUIÇÃo Do SUJEITO NA/PELA REDE SOCIAL

que o instrumento que esta usa para seduzi-la não é suficiente. O que Lacan ([19571958] 1999) adverte é que a mãe, esse ser primordial que possibilita o primeiro contato da criança com esse grande Outro, não pode ser aquela que funciona como lei, porque a lei estaria sujeita à própria mãe, a seu bem-querer e malquerer, a mãe boa ou mãe má.

Para exemplificar, Lacan traz o caso do menino Hans que sofria de fobia e que foi analisado por Freud. Lacan afirma que não se trata da relação pessoal da mãe com o pai para sabermos o que desembocou tal fobia na criança, mas da mãe com a palavra do pai, "[...] com o pai na medida em que o que ele diz não é de modo algum igual a zero" (LACAN, [1957-1958] 1999, p. 197).

O que importa é a função na qual intervém, primeiro, o Nome-do-Pai, o único significante do pai, segundo, a fala articulada do pai e, terceiro, a lei, considerando que o pai está numa relação mais ou menos íntima com ela. $O$ essencial é que a mãe funde o pai como mediador daquilo que está para além da lei dela e de seu capricho...Trata-se do pai, portanto, como Nome-do-Pai, estreitamente ligado à enunciação da lei (LACAN, [1957-1958] 1999, p. 197).

Portanto, nesse terceiro tempo, "[...] o pai pode dar à mãe o que ela deseja, e pode dar porque o possui” (LACAN, [1957-1958] 1999, p. 200). Isto se dá a nível real, o pai tem que dar mostra de sua virilidade. $O$ pai intervém como aquele que tem o falo.

Essa etapa é a saída do complexo de Édipo e que estrutura o sujeito enquanto sujeito desejante, enquanto aquele que está submetido à lei da linguagem.

Esta saída é favorável na medida em que é feita a identificação do menino com o pai (Ideal do eu). "A mulher, contudo, não precisa fazer essa identificação, ela sabe onde está a lei, e vai buscá-la do lado do pai, e vai em direção àquele que o tem" (LACAN, [1957-1958] 1999, p.202). Portanto, a transposição do Complexo de Édipo se dá no menino pela identificação com o pai como possuidor do pênis, e na menina pelo reconhecimento do homem como aquele que o possui.

"Tudo que foi falado aqui leva à conclusão de que no pólo materno começa a se constituir tudo o que depois será realidade (o eu) ao passo que é no nível do pai que começa a se constituir tudo o que depois será supereu (ou Ideal do eu)" (LACAN, [1957-1958] 1999, p. 201). 


\section{A Rede Social Embalando O SuJeito}

Refletir sobre o impacto da revolução tecnológica da Internet, e mais especificamente sobre o uso de redes sociais como o Instagram na construção do sujeito e nas suas relações, no sentido do que o sujeito espera do outro nesse contexto e como demanda a atenção do outro, é pensar na dinâmica do narcisismo.

Quando Freud situa o narcisismo na constituição psíquica do sujeito ele situou a sua importância para o desenvolvimento do eu, caracterizando o narcisismo como "[...] complemento libidinal do egoísmo da pulsão de autopreservação, que, em certa medida, pode justificavelmente ser atribuído a toda criatura viva." (FREUD, [1914]1996, p.81).

No texto "Sobre o narcisismo: uma introdução", Freud (1914), fala que esse momento em que a criança está em ligação indistinta com a mãe, momento de satisfação, a qual ele denomina de eu real, será rompido pelas exigências da cultura que vão marcando a origem de um eu ideal "[...] pelo qual mede seu eu real [...]. Para o eu, a formação de um ideal seria o fator condicionante do recalque. Esse eu ideal é agora o alvo do amor de si mesmo desfrutado na infância pelo eu real" (FREUD, 1914, p.100).

Para ressaltar que estamos destinados a supor que uma unidade comparável ao eu não pode existir desde o começo, o eu tem que ser desenvolvido. As pulsões auto-eróticas, contudo, ali se encontram desde o início, sendo, portanto, necessário que algo seja adicionado ao auto-erotismo- uma nova ação psíquica- a fim de provocar o narcisismo (FREUD, 1914, p. 84).

É esta ação específica que podemos interpretar como aquela que tirara este bebê do desamparo, o acolhendo, possibilitando a estruturação de um eu ainda desorganizado.

No texto "O mal-estar na civilização", Freud (1930) traz o conceito de narcisismo como sendo "[...] a descoberta de que o próprio eu se acha investido pela libido, de que o eu, na verdade, constitui o reduto original dela e continua a ser, até certo ponto, seu quartel-general (1930, p. 122)." Freud, nesse conceito, refere-se à submissão do eu ao Isso logo no início de sua formação, sendo para este, objeto de investimento libidinal. Podemos, com isso, refletir sobre a submissão da criança ao 
INTERNET, NARCISISMO E SUBJETIVIDADE: REFLEXões SOBRE A CONSTITUIÇÃo Do SUJEITO NA/PELA REDE SOCIAL

desejo dos pais que a enxergam como o ideal deles, daquilo que eles foram ou desejavam ser. Para os pais não se trata da criança real, mas da imagem que eles veem refletida naquela criança e que está intimamente ligada à infância deles (FREUD, 1914). Este eu espelhado nestas expectativas dos pais é aquilo que Freud denomina de eu ideal. Este eu fixado pelo convívio na cultura funciona como o fator condicionante do recalque. O sujeito ao crescer

[...] se vê perturbado pelas admoestações de terceiros e pelo despertar de seu próprio julgamento crítico, de modo a não mais poder reter aquela perfeição, procura recuperá-la sob a forma de um eu ideal. O que ele projeta diante de si como sendo seu ideal é o substituto do narcisismo perdido de sua infância na qual ele era seu próprio ideal (FREUD, [1914] 1996, p. 100 101).

Diferente do texto de 1920 em que Freud se ocupa em realizar a distinção entre o mundo externo e o eu, trazendo de modo mais explícito as questões sociais para sua teoria, no texto de 1914, o pai da Psicanálise descreve o processo de constituição do narcisismo pela relação bebê-pais. Freud (1914) explica que o ideal do eu surgiu da influência crítica dos pais ao passo que o eu ideal seria aquele que substitui o eu real. A satisfação experimentada no início da vida, não seria mais revivida, contudo, as marcas libidinais deixadas por esta experiência funcionarão como um motor que levará o sujeito a tentar vivenciar novamente esse período de plenitude.

Sobre o narcisismo primário e o estádio do espelho, Lacan (1936) diz que o mundo que se constitui a partir do estádio do espelho é o narcisismo no qual, para ele, vai além do simples investimento da libido sobre o corpo (como propõe Freud e Abraham). Ele diz que a proposta do estádio do espelho vai mais à fundo, no sentido próprio daquilo que o mito de Narciso vem trazer: "[...] quer esse sentido indique a morte- a insuficiência vital de que proveio esse mundo-, quer a reflexão especular- a imago do duplo que the é central-, quer ainda, a ilusão da imagem- esse mundo, como veremos, não contém o outro" (LACAN, 1936, p. 48).

Podemos sugerir a relação entre os perfis criados em redes sociais com o eu ideal da Psicanálise. Os perfis apresentados nas redes sociais podem, por exemplo, ser editados e reeditados até chegar a uma imagem considerada ideal pelo sujeito, podendo ser enfim colocada para aprovação dos outros. 
Contudo, embora essa hipótese seja verdadeira, ela não pode ser pensada sem ser mais bem analisada, visto envolver questões e conceitos bem complexos. Primeiramente, ressalta-se que a constituição do narcisismo só é possível pela existência de um outro (FREUD, 1914), demarcando no processo constitutivo do sujeito o fato de que o Eu não existe sem o Outro (Linguagem), tal como foi explicado pela metáfora do espelho de Lacan (1998). Freud explica ainda a necessidade que 0 adulto tem de tentar retornar, inconscientemente, a este momento de perfeição que ele outrora vivera, momento em que ele era "a majestade, o bebê!", onde nada parecia Ihe faltar, pois existia a mãe que o satisfazia em tudo. Este Outro que metaforicamente é o espelho, funciona como aquele que autentica e idealiza o Eu da criança (IdealIch).

O Instagram é uma ferramenta que integra diversas funcionalidades, nela é possível ao sujeito trocar mensagens, postar fotos, vídeos, compartilhar arquivos. Além disso, ele tem ainda a oportunidade de acompanhar aquilo que os outros, seu espelho, expõem em suas publicações no feed de notícias. Essas interações na rede social nos fazem refletir sobre o modo como o sujeito é capaz de editar e reeditar aquilo que pode apresentar de si aos outros. A dinâmica do Instagram pode conduzir o sujeito a acreditar que só é possível reconhecer-se nas redes sociais reproduzindo aquilo que é veiculado e midiatizado por seus pares, pois caso não seja assim, provavelmente ele não será aceito, ou utilizando as definições do aplicativos não acumulará likes. Este aspecto autopromocional que o sujeito produz através de seu perfil virtual, promovendo um investimento em si mesmo e na sua própria imagem, pode apontar para uma necessidade de aceitação desse sujeito.

Mediante considerações teóricas tecidas neste trabalho e análise das entrevistas, poder-se-ia inferir que o sujeito contemporâneo apresenta-se cada vez mais narcisista, prisioneiro de uma imagem ideal. Tornou-se um "perfil" que busca e depende a todo o momento do olhar e aprovação alheia para reafirmar-se (CASSIA, 2016, p. 194).

Verificamos que os "likes" e "comentários" são o termômetro da popularidade do sujeito nesse panorama de relações, sendo quesitos influenciadores no processo de construção do perfil desse usuário. A exposição da vida cotidiana na rede social passa a ser uma forma de colocação do sujeito no mundo, no entanto, numa versão 
INTERNET, NARCISISMO E SUBJETIVIDADE: REFLEXões SOBRE A CONSTITUIÇÃo Do SUJEITO NA/PELA REDE SOCIAL

editada e ao gosto do editor, de modo a mostrar-se atraente aos olhos dos outros. Estas modificações de perfis da rede social têm sustentado a teoria freudiana sobre a forma como nosso narcisismo se estrutura, procurando alcançar uma perfeição que outrora vivera, perfeição esta que ele tenta recuperá-la tendo como referência o que Freud denomina de narcisismo primário. "O que ele projeta diante de si como sendo seu ideal é o substituto do narcisismo perdido de sua infância na qual ele era seu próprio ideal" (FREUD, [1914] 1996, p. 100-101).

Tudo isso nos abre possibilidades para pensarmos sobre o uso da tecnologia na produção de discursos e mais ainda, como ela influencia no processo da constituição psíquica do sujeito em meio a um mundo hiper conectado. A sociedade se vê cada vez mais num contexto híbrido, onde mundos online e off-line coexistem e integram o cotidiano dos sujeitos, como afirma Kallas (2016), com o advento das novas tecnologias, estamos presenciando novas formas de ser e estar no mundo, alterando-se noções de espaço, tempo, privado/público, inclusive, de economia do desejo. "O limiar a ser atravessado entre o impulso e o desejo até a ação (o que é visto, baixado, jogado ou comprado on-line) é muito reduzido, o tempo entre escolher e clicar é muito curto e a gratificação é imediata" (KALLAS, 2016 p.56).

A reflexão acima remonta à crítica exposta por Keen (2012) aos que classificavam o período em que vivemos como a "era da inteligência em rede". O autor coloca que a atual geração, embora tenha uma vasta gama de informações à sua disposição, mostra-se apenas subserviente aos saberes de grupos com os quais se identifica, grupos nos quais o sujeito tem tomado partido e reproduzido suas ideias, grande parte delas advindas de fontes como amigos de Facebook, comunidades, grupos de WhatsApp, perfis de famosos e etc. na busca de pertencimento. Devido à pressão da Rede Social e pela necessidade de se sentir integrado cada vez mais ao que é exposto ou exibido no mundo virtual, o sujeito tem aberto mão de produzir mais de si para se tornar um reprodutor daquilo que é veiculado, tornando-se um reflexo daquilo que ele vê no espelho (do computador, do smartphone e de outros).

Ao que nos parece, o mundo midiático das redes sociais trouxe, também, para o cidadão comum a possibilidade, dentre outras coisas, de se colocar enquanto uma celebridade, que pode expor sua vida a partir de uma edição, onde seus seguidores dão likes, comentam, compartilham e retroalimentam essa dinâmica através da 
difusão de uma autoimagem construída que produz efeitos de autopromoção e conferem popularidade ao sujeito. Se antes as pessoas abriam as revistas ou viam nas TVs e na internet o fabuloso mundo dos famosos, os quais eram dignos de inveja, curiosidade e de acompanhamento das rotinas, agora, longe da imprensa, mas providos das tecnologias comunicacionais, o sujeito constrói sua própria "carreira da fama" no Instagram e tem sua publicidade a partir das suas postagens, podendo inclusive sair do anonimato e ingressar no mundo da fama.

Quando se estipula uma relação exibicionismo-voyeurismo, pode-se analisar uma questão bem mais ampla e complexa do que o simples fato de se autopromover. Keen (2012) vai mais a fundo em relação à cultura do exibicionismo, demonstrando o como isso tem se colocado na atual conjuntura social em que vivemos. Primeiramente, ele se remete à proposta arquitetônica de Jeremy Bentham, filósofo utilitarista do século XIX, que idealizou um edifício no qual denominou casa de inspeção, um prédio circular de pequenos aposentos, todos transparentes, conectados entre si, nos quais os indivíduos podiam ser supervisionados por um inspetor que tudo via. Nesse modelo arquitetônico, "[...] quanto mais imaginássemos que éramos vigiados, mais eficientes e disciplinados nos tornaríamos" (BENTHAM, 1995 apud KEEN, 2012, p. 28). Keen (2012) analisa esta proposta para além de uma simples arquitetura, ampliando-a para a visão de vigilância e controle dos indivíduos que ocorre progressivamente no século XIX e XX. Ele fala da tentativa do sujeito de escapar para resguardar sua invisibilidade, tentando fugir das tecnologias de massa que surgiram na era industrial.

Acompanhando o processo sócio-histórico, Keen (2012) afirma que a casa de inspeção benthaniana parece ressurgir no século XXI com algumas importantes diferenças - "o que antes vimos como prisão agora é considerada como parque de diversões; o que era encarado como dor, hoje é visto como prazer" (KEEN, 2012, p. 30), referindo-se à exposição do eu ao olho do outro e demarcando oposição entre a era da exibição (analógica) e a atual era do exibicionismo (virtual). A primeira parecia estar cerceando o sujeito a contragosto, algo semelhante aos olhos do pai disciplinador, modelo típico do patriarcalismo da família nuclear moderna. A segunda se assemelha a um desejo por ser visto. O sujeito não se sente mais despido, ou melhor, parece não se incomodar em ser visto assim, pelo contrário, ele ostenta, ele exibe e, no que exibe, quer ser visto, curtido e compartilhado. Contudo, Keen (2012) 
INTERNET, NARCISISMO E SUBJETIVIDADE: REFLEXões SOBRE A CONSTITUIÇÃo Do SUJEITO NA/PELA REDE SOCIAL

adverte que, embora desde o século XIX as tecnologias estivessem tendo êxito no controle e vigilância do sujeito, este não havia dado seu aval de modo tão solícito e prazeroso como o tem feito na era digital. Agora, devido à conectividade em escala mundial (computadores, celulares, TVs on-line, carros conectados, etc), a possibilidade de controle da massa, por constante observação, está concretizada.

\section{CONSIDERAÇÕEs FinaIS}

O mundo da hiper conectividade tem sido uma marca registrada da era em que vivemos e tem sido fonte de análise para compreensão de um sujeito cada vez mais imerso na cultura da tecnologia virtual. Um exemplo disto é o Instagram - uma das redes sociais de maior destaque e popularidade na atualidade. Algumas ferramentas interessantes dele foram destacadas nesta breve análise que realizamos, dentre elas, a possibilidade que ele dá de o sujeito editar e reeditar uma imagem de si a seu gosto. Contudo, vale frisar que esta liberdade de edição de si mesmo parece ser ainda, cerceada pelo Outro. Este Outro, lugar onde esse sujeito se presentifica-nesse caso, pensamos na presentificação virtual - é aquele que funciona como espelho para formação desse perfil. Este internauta, no processo de exibição, obtém respostas vindas desse lugar de linguagem. E estas respostas são demonstra das por meio de vários formatos - likes, comentários, compartilhamento ou ainda aquilo que esse Outro apresenta na Rede e que funciona como parâmetro de idealização desse sujeito; essa interação social é muito fácil de ser constada, visto que a própria estrutura do Instagram consiste em exibir o perfil do sujeito, proporcionando interação social numa modalidade virtual.

A exibição traz, ainda, ao sujeito a possibilidade de se tornar uma espécie de celebridade, visto que sua vida pode ser acompanhada por outras pessoas. E os engrandecimentos, visualizações, seguidores, podem provocar no sujeito o desejo de se exibir ainda mais, na tentativa de ganhar mais "fama" nesta rede, de ser mais notado, ser fonte de destaque, algo que pode ser explicado pelo que Freud disse ao se referir ao desejo inconsciente do sujeito em retornar ao período em que ele era a fonte de todas as atenções, "a majestade, o bebê". Algo que nunca será alcançada, mas que é sempre almejado, colocando o sujeito num movimento de abertura e de interesse pela autenticação desse Outro. 
Apontamos também neste trabalho a suposta sensação de liberdade que a Rede proporciona ao sujeito - liberdade em expressar sua opinião, seus anseios, seu cotidiano, dentre outras coisas. Essa liberdade abre a possibilidade secundária de se saber onde está o sujeito, o que está fazendo, o que está pensando, etc., tornando a Rede um espaço de vigilância e controle deste sujeito que, ao que parece, na luta pelo enobrecimento de sua imagem tem se tornado sujeito de seu assujeitamento. 


\section{REFERÊNCIAS}

CASSIA, Maria Aparecida de. Entre curtir e compartilhar: um olhar sobre a visibilidade, privacidade e subjetividade contemporânea nas redes sociais virtuais. In: Pretextos: Revista da Graduação em Psicologia da PUC Minas. v.1, n.1, p. 176-198, 2016. Disponível em: http://periodicos.pucminas.br/index.php/pretextos/article/view/13592 . Acesso 10 fev. 2019.

CASTELLS, Manuel. A sociedade em rede. São Paulo: Paz e Terra, 1999.

CASTELLS, Manuel. Comunidades virtuais ou sociedade em rede? In: A galáxia da internet: reflexões sobre a internet, os negócios e a sociedade. Rio de Janeiro: Jorge Zahar, 2003. p.98-113.

FREUD, Sigmund. (1920) Além do princípio do prazer. In: Edição standard brasileira das obras psicológicas completas de Sigmund Freud. Rio de Janeiro: Imago, 1996. v.18.

FREUD, Sigmund. (1930) O mal-estar na civilização. In: Edição standard brasileira das obras psicológicas completas de Sigmund Freud. Rio de Janeiro: Imago, 1996. v.21.

FREUD, Sigmund. (1914) Sobre o narcisismo: uma introdução. [1914]. Edição standard brasileira das obras psicológicas completas de Sigmund Freud. Rio de Janeiro: Imago, 1996. v.14.

KALLAS, Marília Brandão Lemos de Morais. O sujeito contemporâneo, o mundo virtual e a psicanálise. Reverso. Belo Horizonte, v. 38, n. 71, p. 55-64, 2016. Disponível em: http://pepsic.bvsalud.org/pdf/reverso/v38n71/v38n71a06.pdf . Acesso em: 15 mar. 2019.

KEEN, A. Vertigem digital. Rio de Janeiro: Zahar, 2012.

LACAN, Jacques.O estádio do espelho como formador da função do eu. In: Escritos.

Rio de Janeiro: Ed. Jorge Zahar, 1998.

LACAN, Jacques. (1964) O seminário, livro 11: os quatro conceitos fundamentais da Psicanálise. Rio de Janeiro: Ed. Jorge Zahar, 1998.

LACAN, Jacques. (1957-1958) O seminário, livro 5: as formações do Inconsciente. Rio de Janeiro: Ed. Jorge Zahar, 1999.

LACAN, Jacques. (1936) Os complexos Familiares na Formação do Indivíduo. Campo Freudiano no Brasil (Org.). Outros Escritos. Rio de Janeiro: Jorge Zahar Ed, 2013.

LÉVY. Pierre. O que é o virtual?. São Paulo: Ed.34, 1996. 
MUNDOBIT. Facebook tem 89 milhões de usuários brasileiros. 2014. Disponível em: <http://blogs.ne10.uol.com.br/mundobit/2014/08/22/facebook-tem-89-milhoes-de-usuariosbrasileiros/>. Acesso em: 10 mar 2016.

OLHAR DIGITAL. 13 coisas que você não sabia sobre o Facebook. 2014. Disponível em: $<$ http://olhardigital.uol.com.br/noticia/13-coisas-que-voce-nao-sabia-sobre-ofacebook/42911>. Acesso em: 10 mar. 2016.

TARDÁGUILA, Cristina . Instagram tem 1 bilhão de usuários, mas não oferece sistema de denúncia de fake news. Época. 14/01/19. Disponível em: https://epoca.globo.com/instagramtem-1-bilhao-de-usuarios-mas-nao-oferece-sistema-de-denuncia-de-fake-news-23370668 Acesso em: 15 fev. 2019. 


\title{
INTERNET, NARCISSISM AND SUBJECTIVITY: REFLECTIONS On The Constitution Of The SubJect In/By The Social NETWORK
}

\begin{abstract}
The potential of internet for hyperconnectivity has brought reflections not only to the lifestyle of societies, but also to the subject's own construction and modes of subjectivation in contemporary times. That context, we highlight the use of social networks, as Instagram, which expanded rapidly, becoming a worldwide phenomenon, and that is part of this new context of construction of subjectivity. This article is a theoretical essay, whose objective was to sketch a look at the constitution of the subject, considering here the aspects of psychoanalytic theory, glimpsing possible links between this theory and the hyperconnectivity aspects of social networks where this subject is Immersing, especially on Instagram.
\end{abstract}

KEYWORDS: Internet; Social networks; Instagram; Subjectivity; Narcissism. 


\section{INTERNET, NARCISSISME Et SUBJECTIVITÉ: RÉFLEXIONS SUR La Constitution Du Sujet Dans le Réseau Social}

\section{RÉSUMÉ}

Internet, avec son potentiel d'hyperconnectivité, a apporté des réflexes non seulement au mode de vie des sociétés, mais également à la construction même du sujet et à ses modes de subjectivation à l'époque contemporaine. Dans ce scénario, nous soulignons l'utilisation des réseaux sociaux, comme Instagram, qui se sont rapidement développés, devenant un phénomène mondial et faisant partie de ce nouveau contexte de construction de la subjectivité. Le présent article est un essai théorique dont l'objectif était de donner un aperçu de la constitution du sujet, en considérant ici les aspects de la théorie psychanalytique, en discernant les liens possibles entre cette théorie et les aspects liés à l'hyperconnectivité des réseaux sociaux où se trouve ce sujet. immersion, en particulier dans Instagram.

Mots-CLÉS: Internet; Réseaux sociaux; Instagram; Subjectivité; Narcisisme. 
RECEBIDO EM 22/07/2019

APROVADO EM 22/06/2020

(C) 2020 Psicanálise \& Barroco em revista

http://www.seer.unirio.br/index.php/psicanalise-barroco/index revista@psicanaliseebarroco.pro.br

Programa de Pós-Graduação em Memória Social — UNIRIO

Memória, Subjetividade e Criação

www.memoriasocial.pro.br/proposta-area.php 